NASA Technical Memorandum 88959

AIAA-87-0739

\title{
Analytical and Experimental Investigation of Mistuning in Propfan Flutter
}

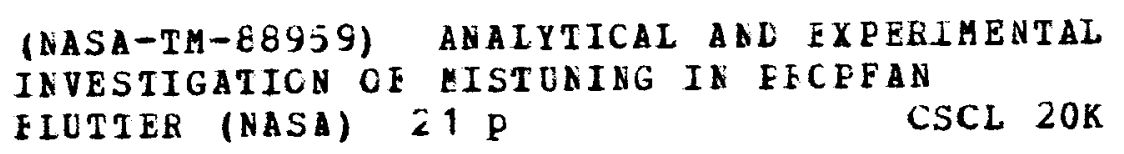

Krishna Rao V. Kaza and Oral Mehmed

Lewis Research Center

Cleveland, Ohio

Marc Williams

Purdue University

West Lafayette, Indiana

Larry A. Moss

Sverdrup Technology, Inc.

Lewis Research Center

Cleveland, Ohio

Prepared for the

28th Structures, Structural Dynamics, and Materials Conference

cosponsored by the AIAA, ASME, AHS, and ASEE

Monterey, California, April 6-8, 1987 


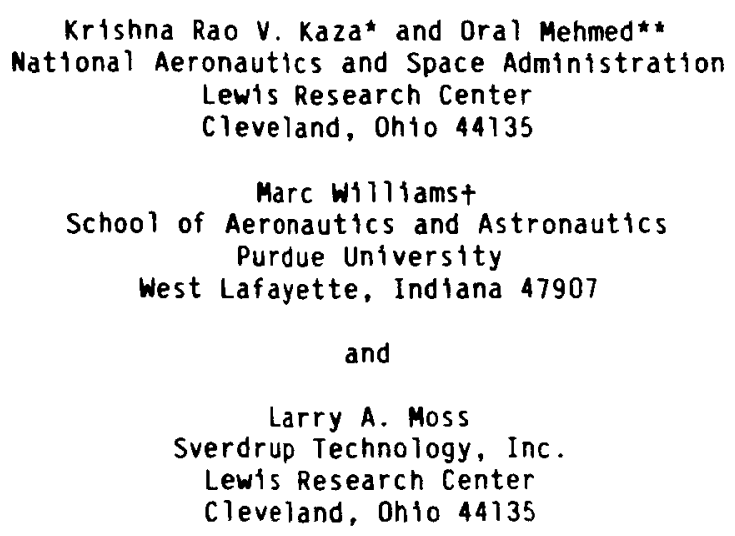

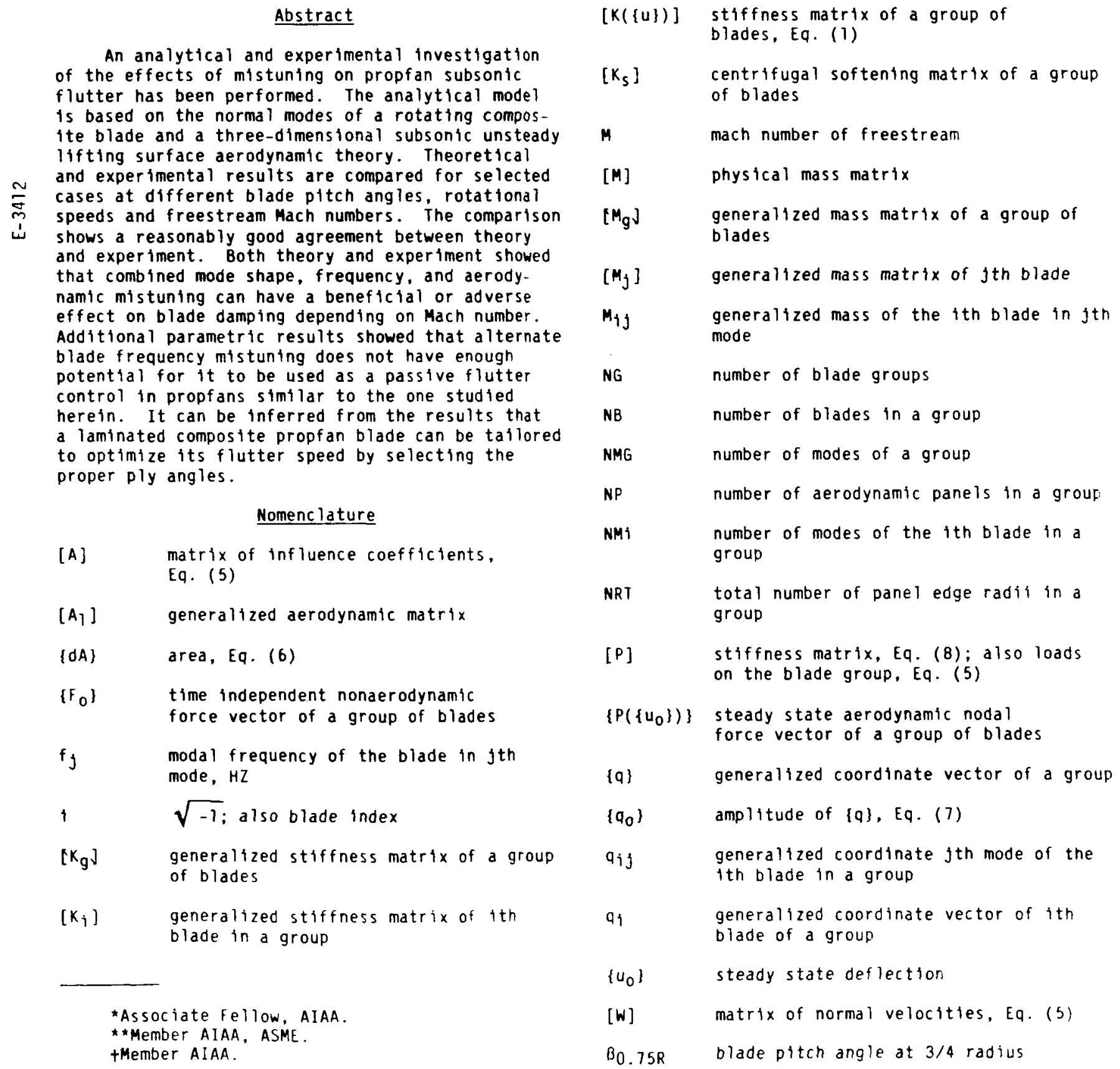


$\{\Delta u(t)\} \quad$ vibratory deflection vector at grid points measured from steady state

normal displacement, Eg. (6)

damping radio in $j$ th mode of ith blade in a group

$\mu$

$o_{r}$

$\sigma_{G 1}$

Imaginary part of eigenvalue

real part of eigenvalue

Interblade phase angle between the blades of a group

intergroup phase angle between like blades from group to group.

$1=0,1,2, \ldots(\mathrm{NG}-1)$

[ $\left.\phi_{1}\right]$ model matrix of 1 th blade in a group

wif frequency of the fth mode of the ith blade

\section{Introduction}

Research on propfan aeroelasticity is a continuing effort at NASA Lewis Research Center. Until now the analytical work has involved propfans with blades of assumed identical properties. This paper continues that work for propfans with blades of different properties.

A flutter study of a propfan wind tunne 3 model with ten titanium blades under transonic tip cond 1 . tions was reported in Ref. 1. Analytical comparisons to the flutter data, presented in Ref. 1, were reported in Refs. 2 and 3 . Additional flutter data from a model with etght composite material blades in subsonic flow was reported in Ref. 4.

A more refined analysis than those of Refs. I to 3 is described in Ref. 5. The analysis makes use of recent developments in modeling of composite material, 6 vibration analys is under rotating conditions including geometric nonlinearities, 9 and both steady and unsteady three-dimensional subsontc cascade aerodynamic models. 8 Additionally. Ref. 5 correlates predicted flutter results with the measured data reported in Ref. 4 for a propfan with eight identical composite blades.

In the analytical aeroelastic models described in Refs. 1 to 3 and 5 , it is assumed that all the blades have identical structural and aerodynamic properties. Consequently, there is no coupling between the interblade phase angle modes. Then, each mode can be analyzed independentiy for flutter and forced response of the rotor. However, in practical propfans propertles differ from blade to blade because of manufacturing limitations. The presence of smali differences between the blades is known as mistuning. Mistuning couples the intert ade phase angle modes, and introduces complextiy in the dynamic andysis.

Understanding the effects of blade mistuning on vibration, flutter and forced response of turbo machinery blade-disk assemblies has recelved con. siderable attention and is a current research topic in turbomachinery aeroelasticity. 9-14 The domi. nar: reasons for illis at:ention are: (1) it does affect flutter and forced response; and (2) inten tional mistuning may have potential as a passive control to increase flutter speed and minimize system response.

Several questions arise concerning the role of mistuning in propfan flutter. Specifically: (1) Does the presence of sweep and strong bending torsion coupling between the blade structural modes influence the role of mistuning? (2) Does mis tuning have enough potential to be used as a passive control to alleviate flutter? (3) Does the presence of mistuning have any influence on blade loads? To answer the first two questions partially. an analytical and experimental investigation was conducted. The analytical effort involves an extension of the flutter model described in Ref. 5 to include both structural and aerodynamic mistuning. The structural model for each blade is defined by blade geometry, normal modes, frequen. cles, and generalized masses. The derodynamic model is based on three-dimensional subsontc lift. ing surface theory. 8 The models account for differences in blade properties such as geometry, pitch angle, sweep, modes, frequencies, and damp. ing. The type of mistuning in the analytical flutter model is arbitrary.

A wind tunnel experiment was performed. An eight-bladed mistuned rotor was constructed by alternately mounting two sets of composite blades of two geometrically and materially similar rotors. The first set of four blades, SR3C-X2, are from the rotor described in Ref. 4. The second set of blades, SR3C-3, are identical to the first set except for the ply angles of the composite mate rial. Because of the ply angle difference. the experimental rotor had a particular type of alter. nate blade mistuning which is characterized by the differences in blade frequencles, mode shapes, steady state geometry, damping, and steady and unsteady air loads.

Flutter speed, flutter frequencles, and flutter interblade phase angles were measured in the wind tunnel at various blade pitch angles. Mach. numbers, and rotational speeds. Also measured during the test were blade strain amplitudes which will not be addressed in this paper.

This paper presents the analytical formulation of the flutter model, describes the wind tunnel model and experiment, outlines the application of the formulation to the wind tunnel model, and com pares calculated and measured in-vacuum nonrotating frequencies and modes. Also compared in the paper are calculated and measured flutter speeds, flutter frequencies, and interblade phase angles. Finally. the potential for alternate frequency mistuning as a passive flutter control is assessed.

\section{Analytical formulation}

The aeroelastic analys is of propfans is inher entiy nonlinear because of rotation, and requires a geometric nonlinear theory of elasticity. By using a fintte element structural model and three dimenstional steady and unsteady cascade aerodynamic models, an aeroelastic model for a propfan with a rigid hub and identical blades was developed in Ref. 5. That model has been generalized for a propfan with a rigtd hub and with structurally and aerodynamically mistuned biades. Since the basis detalls were given in Ref. 5 , only an outline of 
the development and of spectal modifications which are essential to allow mistuning are discussed here.

\section{Equations of Motion of a Mistuned Propfan}

An aeroelastic model with frequency mistuning was developed in Refs. 10 to 13 by exploiting the perlodic structure of the aerodynamic model for a rotor with geometrically identical blades by using two-dimensional unsteady cascade aerodynamic

theory. Aerodynamic mistuning with supersonic twodimensional unsteady cascade aerodynamic theory was addressed in Ref. 14. Since the present formulation does not distinguish between aerodynamic and structural mistuning and uses the normal modes of a rotating structure in conjunction with threedimensional unsteady aerodynamic theory, a slightiy different and more general approach than that used in Ref. 10 is adopted.

In the present formulation, the propfan is assumed to have NG identical groups of blades symmetrically distributed about the disk. Each group contains NB blades (disjoint surfaces) which need have no special geometric or spatial relationship to each other. A schematic for an eight-bladed rotor with four blade groups is illustrated in $\mathrm{Fig}$. I. A tuned rotor, then, corresponds to $N B=1$, in which case $N G$ is the total number of blades. Conversely, if $N G=1$, then each of the blades, NB in number, is treated individually. In general, it is assumed that the groups vibrate with an identical motion, but with a constant intergroup phase angle, which may take any of the values $\sigma_{G 1}=2 \pi 1 / N G, 1=0,1, \ldots, N G-1$. Generalizing the steady state single blade equation in Ref. 5, the corresponding equation for any group is

$$
\left[\left[K_{s}\right]+\left[K\left(\left\{u_{0}\right\}\right)\right]\right]\left\{u_{0}\right\}=\left\{P\left(\left\{u_{0}\right\}\right)\right\}+\left\{F_{0}\right\}
$$

The form of Eq. (1) is the same as the corresponding one in Ref. 5, but the orders of the matrices and of the displacement vector are different. The stiffness and force matrices in $\mathrm{Eq}$. (1) represent the entire blade group. For example, for a propfan with eight blades (four groups with two blades in each group) 228 grid points for each blade, and six degrees of freedom for each grid point, the total number of degrees of freedom of Eq. (1) is 2736 . Furthermore, the equation is nonlinear involving large deflections, centrifugal and steady state alrloads. The solution requires substantial computer time. To reduce that time, the steady state derodynamic loads have been neglected herein. (The effect of these steady airloads for a tuned rotor is addressed in Ref. 5.) With this assumption, the steady aerodynamic coupling between the blades in a group is elliminated from the flutter analys is. Consequently, the steady state deflections and the differential stiffness of each blade in a group can be calculated independently by using Eq. (1) with. out steady airloads. The procedure for these calculations is the same as that described in Ref. 5 . The vibration modes and frequencles of each blade in the group are calculated independently by using the following equation, which is also discussed in Ref. 5.

[M] $\{\Delta \ddot{u}(t)\}+\left[\left[K_{s}\right]+\left[K\left(\left\{u_{0}\right\}\right)\right]\right]\{\Delta u(t)\}=0$
The next step in the formulation of the aero elastic model by the modal method is to generalize the single blade equation of Ref. 5 to NB blades in a group. Assuming simple harmonic motion and following the procedure in Ref. 10, the aeroelastic equations for NB arbitrarily mistuned blades in a group are

$$
\left[M_{g}\right]\{\ddot{q}\}+\left[K_{g}\right]\{q\}=\left[A_{1}\right]\{q]
$$

Again, the form of Eq. (3) is the same as the corresponding one of Ref. 5, but the orders of the matrices and of the generalized coordinate vector are different. The new definitions are as follows:

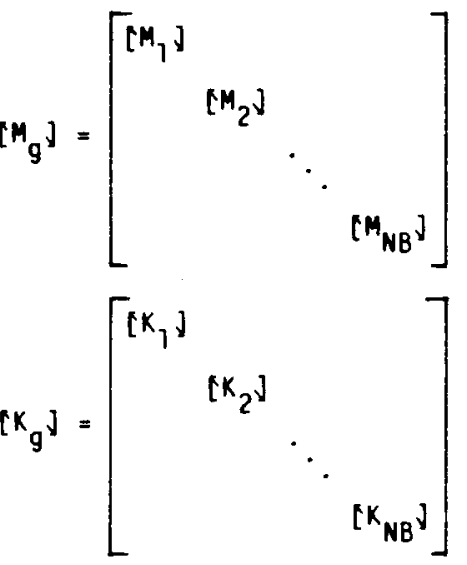

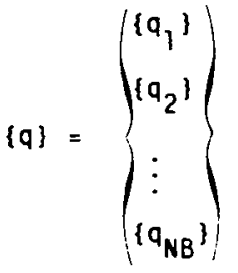<smiles></smiles>

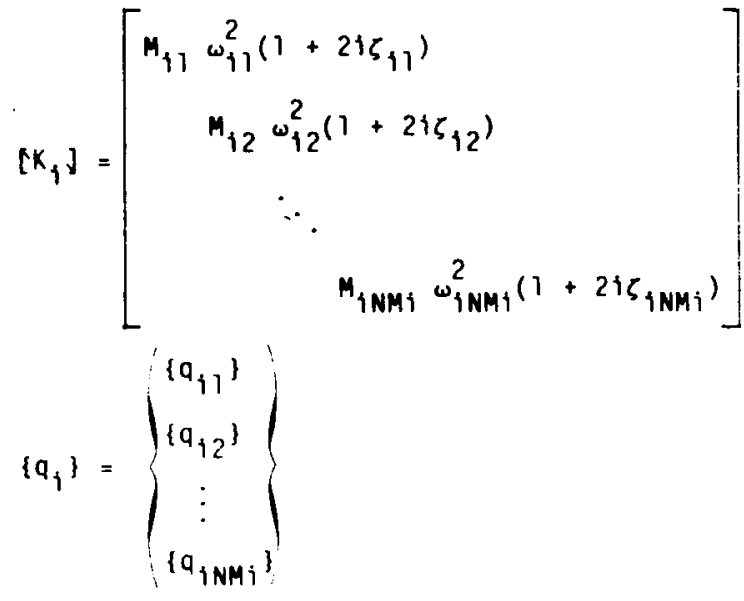

$\left\{\Delta u_{i}(t)\right\}=\left[\phi_{j}\right]\left\{q_{i}\right\}$ 
The coefficients $M_{1 j}, w_{1 j}$, and $\zeta_{i j}$ are the generalized mass, the corresponding frequency, and the corresponding damping ratio, respectively, of the $j$ th normal mode of the ith blade in a group. The suffix NMi represents the number of blade normal modes consldered for the ith blade in the flutter analysis. The quantities $\left[\phi_{1}\right]$ and $\left\{a_{1}\right\}$ are the normal mode matr $\{x$ and generalized coordinate vector for the ith blade in a group. The detalls for the development of the aerodynamic matrix $\left[A_{1}\right]$ are given in the following section.

\section{Unsteady Aerodynamic Mode]}

The generalized aerodynamic force matrix in Eq. (3) has been computed with the threedimensional compressible lifting surface theory described in Refs. 8, 15, and 16. Since the detalis of the scheme are given in those references, only an outline of the method and the speclal mistuning modifications will be discussed herein.

The numerical method is based on an assumed inearization of the flutd motion about a uniform steady flow. The disturbance generated by the rotor blades is presumed to be simple harmonic in time in a reference frame rotating with the blades. Each wake is assumed to be rigid and to lie in the helical surface swept out by the blade trafling edge. These assumptions result in a linear integral equation relating the normal velocity of the surface of the blades to the load (differential pressure) acting on the blades. The integral equation is solved by a piecewise constant load panel method.

For simplictiy, the effects of hubs and nacelles are ignored, as is blade thickness. The blades are, in effect, treated as loaded helical surfaces with no thickness. As in any linear aero. dynamic theory, the unsteady loads induced by blade vibration are mathematically decoupled from the steady loads arising from blade incidence.

The use of linear aerodynamic theory limits the applicablitty of the method to lightly loaded conditions (unstalled) and to Mach numbers at which transonic effects at the blade tips are not significant. In addition, the rigid wake approximation breaks down at low advance ratios, where induced velocities may have a strong influence on the wake structure (which in turn may significantly modify the blade loading.) of course, one usualiy does not know apriorl whether such effects wlll be present at a given operating point, so some caution in interpreting the results is necessary.

In the original code, Ref. 5, on which the present method is based, it is assumed that the rotor contains NG equaliy spaced identical blades. which vibrate with identical motion but with a constant interblade phase angle, one of the set $2 \pi 1 / N G, 1=0,1, \ldots N G-1$. In the present version, mistuning is accounted for by the simple expedient of redefining a blade as a group of NB identical blades. Then these groups are symmetrically dis. tributed about the disk.

The geometry and vibration mode data is usually obtained by solving Eas. (1) and (2) with NAs, IKAN. Fach blods is translated alung ar:! rotated about the axis of rotation, and rotated about its pitch change axis, so that it lies in the desired position and orientation. The group is paneled by placing a fixed number, NXP, of quad rilateral panels on each radial interval $r t(j)<r<r t(j+1), j=1, \ldots$ NRT (unless $r t(j+1)<r t(j)$, which signals a jump from the tip of one blade to the root of the next). Thus, except for the deletion of $t$ ip-root connections, the group is effectively treated as a single surface with NP = NXP* (NRT - NB) panels.

The definition of group vibration modes requires special mention. Essentially, one group mode consists of one blade in the group vibrating in one of its natural modes while all other blades in the group remain fixed. Suppose the $j$ th blade in a group is assigned NMj vibration modes. The group as a whole, then has NMG $=N M 1+N M 2+\ldots$ + NMNB modes. The group made NMI + 1 , for example, corresponds to the second blade in the group vibrating in its first mode, while all remaining blades are stationary.

In general, let $W(n, k)$ denote the normal velocity at the nth control point in the $k$ th group mode. This array is initialized to zero and then loaded sequentially with the NMl values of first blade modes $\left[\Phi_{1}\right]$, at control points on the first blade, the NM2 values of second blade modes, $\left[\Phi_{2}\right]$, at control points on the second blade, and so on.

The aerodynamic loads can then be found by solving the linear algebra problem:

$$
\text { [A] }[P]=[W]
$$

where [A] is the (NP,NP) matrix of influence coefficients, [W] is the (NP. NMG) matrix of normal velocities, and [P] is the (NP. NMG) array of loads on the blade group. The influence coefficient matrix contains the interference between blade groups and, therefore, depends on the intergroup phase angle (as well as the vibratory frequency.) Thus, separate solutions are required for every intergroup phase angle and frequency of interest.

Once the load distribution has been found, the generalized force matrix can be determined by simple numerical integration over the blade group:

$$
\left[A_{1}(n, m)\right]=\sum_{j=1}^{N P}[P(j, m)][\delta(j, n)]\{\delta A(j)\}
$$

where $P(j, m)$ is the load on the $j$ th panel (with area $d A(j))$, assoctated with the $m$ th group mode, and $\delta(j, n)$ is the normal displacement of the sur face at the control point of the $f$ th panel in the nth mode.

\section{Solution}

For simple narmonic motion

$$
\{a\}=\left\{a_{0}\right\} e^{i \omega t}
$$

Eq. (3) leads for the following:

$$
\text { [P] }\left\{a_{0}\right\}: Y[M g]
$$


where

$$
\begin{aligned}
& {[P]=\left[K_{g}\right]-\left[A_{]}\right]} \\
& 1 \sqrt{Y}=[\omega=\mu+1 v
\end{aligned}
$$

Flutter occurs when $\mu=0$. The eigenvalue problem, Eq. (8), is solved for a given rotational speed and blade pitch angle and by using the procedure and the computer program, ASTROP3, described in Ref. 5, for each of the possible intergroup phase angles. Then, the flutter intergroup phase angle is the one for which the flutter Mach number is the lowest. The interblade phase angle in the group is determined from the corresponding efgenvector $\left\{q_{0}\right\}$. From the calculated intergroup and interblade phase angles, the interblade phase angles of the entire rotor are determined.

\section{Description of Experiment}

The experiment was conducted in the NASA Lewis 8-by-6 ft. (2.44-by-1.83-m) wind tunnel. Test conditions included tunnel Mach numbers from 0.36 to 0.75 and rotor speeds up to $8000 \mathrm{rpm}$. The propfan models were mounted on a single rotation, isolated nacelle test rig and driven by an alr turbine. Blade mounted strain gauges provided blade vibratory strain signals. Elght blades were mounted in a hub which can be considered rigid. Fig. 2 shows the test rig installed in the wind tunnel.

Two existing propfan research models, SR3C-X2 and $S R 3 C-3$, of $0.62 \mathrm{~m}(2 \mathrm{ft})$ diameter were used for this experiment. The blades were molded from graphite-ply/epoxy-matrix laminated material. Both models had 80 percent of the plys in the blade pitch axis $\left(0^{\circ}\right)$ direction, as shown in Fig. 3 . The remaining piys were distributed at the $\pm 22.5^{\circ}$ directions for $S R 3 C-X 2$, and at the $\pm 45^{\circ}$ directions for SR3C -3 .

The models were individually wind tunnel tested prior to the present experiment. The SR3C-X2 model fluttered and the SR3C-3 did not within the operating conditions of the test (tunne? Mach $=0.9$ and $10000 \mathrm{rpm})$. The observed behavior of the two models differed because of frequency and mode shapes differences, which were, in turn, caused by the ply angle differences. Experimental results from the previous SR3C-X2 experiment were reported in Refs. 4 and 17. Analytical results were reported in Refs. 5 and 17 for the SR3C-X2 and in Ref. 17 for the SR3C-3.

The present experiment was conducted in two parts, following the test procedure described in Ref. 4. First, the eight-bladed SR3C-X2 rotor was tested. This part is a repetition of the test reported in Ref. 4 and was done because of changes in measured blade natural frequencles and mode shapes after the prevlous flutter test. The average blade first and secand mode frequencies (nonrotating) dropped by 5 and 1 percent, respectively, because of the blade material degradation from the large vibratory motion during flutter. Second, a mixed rotor, SR3C-X2/SR3C-3, was tested to obtain the flutter boundary of a configuration of blades with different frequencies and mode shapes. This rotor was constructed by alternately positioning four SR3C-X2 blades and four SR $3 C-3$ blades. The SR $3 C-X 2$ rotor can be considered tuned and the mixed rotor mistuned based on "ne differences betheen measured frequencles and mode shapes. These differences w111 be olscussed later.

\section{RESULTS AND DISCUSSION}

The calculated and measured results for the SR $3 C-X 2$ and $m 1 x e d$ rotors are presented in five parts: (1) measured nonrotating blade frequencies and mode shapes; (2) calculated blade rotating frequencies; (3) calculated root locus plots; (4) calculated damping plots; (5) calculated and measured flutter results. Also, the calculated flutter characteristics for an alternately frequency mistuned SR3C-X2 rotor are presented.

In all the calculations the steady state deflections, frequencles and mode shapes of the blades were obtained by using COSMIC NASTRAN. All the calculations are made by using the steady deflected position of the blade under centrifuga? loads only. Only the first two modes for each blade were considered because, as will be shown later, the flutter mode is primarily a combination of these two modes. Also for unsteady aerodynamic calculations each blade is discretized with nine (radial) times eight (chordwise) panels.

Nonrotating Blade Natural Frequencles and Mode Shapes

The natural frequencies and mode shapes of the SR3C-X2 and -3 model differ because of the ply angle vartation between the blades. Table I summarizes the measurements of the first two nonrota. ting natural frequencies of the SR3C-X2 and -3 blades for both rotor configurations. The first mode frequencles of both the blades are very close and were insensitive to the variation of ply angles. However, the average second mode frequency of the SR3C-3 blade is about 12 percent higher than that of the $-\times 2$ blade.

Figure 4 shows the nonrotating $S R 3 C-X 2$ and -3 blade displacement contours for the first two natural modes. Here, there is a difference between the inclination of the first mode contour lines of the blades. The greater inclination of the SR3C-X2 contour lines indicates a greater torsional motion of the blade. The contour lines of the second modes of both blades are similar and show tip torsion. Thus, there are differences in the mode shapes of the SR3C-X2 and -3 blades, and the dif. ference is more significant for the first mode. The calculated and measured mode shapes are in fair agreement for both the blade models.

A variation around the rotor of natural frequencies existed for both the SR3C-X2 and the mixed rotors but a mode shape variation of significance existed only for the mixed rotor. However, no attempt was made to quantify the mode shape differ ences. The variation of the nonrotating measured first and second natural frequencles around the rotors are shown in Fig. 5. For the SR3C-X2 rotor. the largest natural frequency differences occurred between blades 2 and 3 (first mode, 6.5 percent: second mode, 5.5 percent). Whereas, for the mixed rotor, the largest difference occurred between blades 3 and 4 (first mode, 2.7 percent; secono mode, 14.3 percent). Hence, the frequency mistuning was higher in the first mode for the SR3C. X2 rotor and higher in the second mode for the mixed rotor. 
Blade Frequency Variation with Rotational Speed

Figures $6(a)$ and (b) show the variation with rotational speed of the blade frequencies in vacuum for the SR3C-X2 blade and the SR3C-3 blade respectively. The nonrotating average measured frequenctes from Table I are also shown. The results show an increase in the first mode frequency with rotational speed, whereas, the second mode frequency is relatively constant unt $116000 \mathrm{rpm}$ and then increases slightly. This is expected because the first mode is primarily bending, which is affected by rotational speed, whereas, the torsion mode is relatively insensitive to rotation. The results shown are for the $61.2^{\circ}$ blade pitch angle. Results, although not shown, for a $68.0^{\circ}$ blade angle are very close and follow the same trends as in figs. 6(a) and (b). This indicates insensitivity of the frequencles to a blade angle variation of this order. It should be mentloned that there is a problem in estimating the equivalent anisotropic material properties, because of the unknown blade materlal properties after fabrication. When the material manufacturers' specifled properties of the composite material were used in calculating blade nonrotating frequencles, the frequencies were higher than those measured. Therefore, to obtain better agreement the material constants were adjusted.

\section{Calculated Root Locus Plots}

To 1 llustrate the effect of mistuning (which is partly aerodynamic and structural) the calculated real and imaginary parts of the eigenvalues of the SR3C-X2, SR3C-3 and mixed rotors were compared. The mistuning is due to the differences in blade steady state geometry, frequencles, and mode shapes. The steady state geometry of the biades in a group differs because the steady deflections due to centrifugal loads are different. The eigenvalues are for all interblade phase angles of the mode with lowest damping at the critical Mach number and critical reduced frequency of the SR3C- $X 2$ rotor. The calculations were performed by treating the $S R 3 C-X 2$ and $S R 3 C-3$ rotors as tuned and the other one as mistuned with both structural and aerodynamic mistuning. Furthermore, the mixed rotor is modeled as an idealized alternately mistuned rotor -- four identical blade pairs with two different blades in each pair. The effective dampIng ratio of each interblade phase angle mode is given by the ratio of the real and imaginary parts of that mode.

The comparison of the root loct for the $S R 3 C-X 2$ and $S R 3 C-3$ rotors $(F 1 g .7)$ reveals two interesting points. First, the area of the approximate ellipse for the SR3C-X2 is greater than that of the SR3C-3. Indicating a stronger aerodynamic coupling between the blades of the SR3C-X2 rotor. Second, at the chosen Mach number the SR3C-X2 rotor is neutrally stable and the SR3C- 3 rotor is stable. This difference in stablitity may be attributed to the differences in blade stiffness and mode shapes and to the degree of aerodynamic coupling between the normal modes of the blades. The blade stiffness and mode shapes are different because of the different ply angles of the blades. Thus, one can infer that a laminated composite propfan blade can be tallored to maximize its flutter speed by selecting the proper ply angles. A compartson of the eigenvalues ( $\mathrm{F}+\mathrm{g} .7$ ) for the SR3C-X2. SR3C. 3 , and $m i x e d$ rotors shows that mixing the blades significantly affected the eigenvalues and resulted in a rotor with a greater damping than the lowest damped mode of either pure rotor.

The aerodynamic coupling between the modes of neighboring blades is virtually eliminated in the $\mathbf{m i x e d}$ rotor. The effective damping of some interblade phase angle modes is increased while that of others is decreased. Additionaliy, the root locus plot of the mixed rotor is divided into high and low frequency compact groups such that the effective damping of each interblade phase angle of each group is almost the same. The high frequency group of elgenvalues lies inside the SR3C-X2 ellipse and the other group inside the SR3C-3 ellipse. It is the effect of the aerodynamic coupling of the modes of both the SR3C-X2 and -3 blades in the mixed rotor that give the low and high frequency eigenvalue clusters. The modes of the high frequency cluster involve motion primarily of the SR3C $-X 2$ blades and the modes of the low frequency cluster involve motion primarliy of the -3 blades. The close spacing of the eigenvalues in each group shows that the aerodynamic coupling between neighboring blades (the cascade effect) has been nulli. fied. Note that both the 180 and $225^{\circ}$ interblade phase angle modes are neutrally stable for the SR $3 C-X 2$ rotor. But, the flutter frequencies are different.

To see the effect of Mach number on root loct, the calculated root locus plots (not shown) for the three rotors were also compared at the critical Mach number and reduced frequency of the mixed rotor. For this case the root locus of the SR3C-X2 rotor shown in fig. 7 moved to the right, such that four of the interblade phase angle modes are in the unstable region. But, the root locus of the SR3C-3 rotor moved very little. Also, the cluster of four higher frequency elgenvalues of the mixed rotor remained centered in the SR3C $-X_{2}$ ellipse and, hence, moved close to the neutral stabllity itine. But, the other cluster, remaining roughly centered in the SR3C- 3 locus, moved very little. This shows that the change in damping of the modes in the high frequency cluster is more sensitive than the low frequency cluster to the increase in Mach number. The effect of Mach number on damping will be further discussed in Fig. 8.

In sumbry, the mistuning has increased the damping of the lowest damped modes of both the pure rotors and has nullified the cascade effects. These are the same trends that have been found for turbofan rotor in Ref. 10, although these propfans have fewer blades, lower gap-to-chord and mass ratios, and mode shape and aerodynamic mistuning.

\section{Calculated Damping}

Figure 8 shows the varlation of the real part of the etgenvalue (which 15 proportional to damp ing) with freestream Mach number at $\Omega=6320 \mathrm{rpm}$ and $B_{0} .75 R=61.2^{\circ}$ for the lowest damped mode of the SR3C-X2, SR3C-3, and the mixed rotors. Damping curves for the 180 and $225^{\circ}$ interblade phase angle modes of the SR3C-X2 rotor are shown because both the modes become unstable at the same Mach number. Note that there are two curves for the mixed rotor: one for the low frequency cluster and the other for the high frequency cluster of fig. 7 . 
If the mixed rotor is considered to be developed by perturbation from the SR3C-X2 rotor, the damping of the least stable mode has increased for all the mach numbers shown. If the mixed rotor is constdered to be developed by perturbation from the SR3C-3 rotor the change in damping depends on the Mach number. For Mach numbers between 0.40 and 0.55 the damping has increased. Beyond Mach numbers of 0.55 the damping of the high frequency mode of the mixed rotor is greater than that of the low frequency mode and is less than that of the SR3C-3 rotor. The change in the damping from each of the pure rotors is 11 lustrated by the arrows in the figure. Thus, the mixing of the two sets of blades has a benefictal effect on damping with respect to both of the pure rotors between Mach numbers of 0.40 to 0.55 . Whereas, above 0.55 Mach number the mixing has a beneficlai effect on the damping with respect to the SR3C $-X_{2}$ rotor but an adverse effect on the damping with respect to the SR3C-3 rotor.

\section{Flutter Results}

Experimental and calculated flutter boundaries are correlated in $\mathrm{Fig} .9$ for $B_{0.75 R}=61.2^{\circ}$. Results for the SR3C-X2 and mixed rotors are included. The calculated boundary for each rotor was obtained with the calculated modes and frequencles, except that the measured second mode frequency was substituted for the calculated one. The calculated flutter Mach numbers for the SR3C-X2 are less than the measured ones for all rotational speeds. The agreement between theory and experiment is expected to be better if the effects of steady state aerodynamics and the structural damping are included in the analysis (see Ref. 5 for detalied discussion). The agreement for the mixed rotor is better (with the present theory), but would become unconservative if steady-state aerodynamic loads and structural damping were included in the theory

The correlation of measured and calculated flutter frequencies at a blade angle of $61.2^{\circ}$ is given in Figs. 10 (a) and (b) for the SR3C-X2 and the mixed rotors, respectively. The flutter frequencles are shown on a Campbell diagram which includes the calculated frequencles for the first two modes of the blades, as well as the 2P, 3P, and $4 P$ harmonic order excitation lines of rotational speed. For both figures, the calculated flutter frequencies are higher than the measured frequencles by about $30 \mathrm{~Hz}$, but the slopes of the analytical and measured flutter frequency lines are about the same. The fact that both the calculated and measured frequencies lie between the first and second normal mode frequencles shows that the flutter mode involves a coupling between these two modes.

Measured and calculated phase angles for the mixed rotor are shown in Table Il for three conditions. The measured values were obtained from cross-spectra of blade strain gauge signals. The coherence values assoclated with the phase angles were not always good and only phase angles with coherence values greater than 90 percent are shown. The data shows that several interblade and intergroup phase angles are present during flutter and that there are no predominant intergroup or inter: ade phase angles. The analys is also, howed that several interblade and intergroup phase angle modes were very lightly damped, however, only the lowest damped mode is shown in Table II. So qualitatively the theory and experiment are in agreement, however, the lack of quantitative agreement may be due to the fact that the analytical model assumes identical properties for all the blade groups whlle the actual rotor has differences between blade groups. For example, the differences of blade frequencies is lllustrated in Fig. 4 .

The results shown in Figs. 9 and 10 and Table II were also calculated and measured for $B_{0.75 R}=68^{\circ}$. Although not shown, these results reveal simflar trends and correlation between theory and experiment. However, the flutter speeds are greater by approximately 0.04 Mach number for the blade angle of $68^{\circ}$. In summary, the overall agreement between theory and experiment is reasonably good.

Calculated Flutter Characteristics of an Alternately Frequency Mistuned Rotor

The flutter results presented in Fig. 7 for the SR3C-X2 rotor shows that the aerodynamic cascade effects is significantly destabilizing. Quantitatively, the destabilizing effect is approximately proportional to the length of the semimajor axis of an ellipse formed by joining all the elght points. This destabilizing cascade effect was shown to be present, even for a four-bladed rotor in Ref. 5. Since the potential beneficial effect on damping of frequency mistuning in a turbofan rotor (Ref. 10) is directly proportional to the adverse effect of aerodynamic cascade effects, it is natural to ask whether a similar relationship between cascade and mistuning effects exists for propfan rotor. To answer this question, six configuration cases, as shown in Table III, of the SR3C-X2 rotor are considered. The calculated flutter Mach number, flutter frequencles and flutter interblade phase angles are included in this table. The rotor in case 1 is the reference rotor. In order to confirm the importance of cascade aerodynamic effects, the results of eight, four, and one-bladed tuned rotors (Cases 1,2 , and 3) are compared. Evidently, the flutter Mach number decreases with increasing number of blades. The decrease in flutter Mach number due to cascade effects with eight blades is 0.10 .

In order to evaluate the sensitivity of flutter Mach number to blade frequency changes, a 11 blade frequencies are decreased by 10 percent for the rotor in Case 4 and are increased the same percent for the rotor in Case 5. The flutter Mach number for the case 4 is decreased from 0.53 to 0.46 and for the case 5 is increased from 0.53 to 0.59 , showing that the flutter Mach number is sensitive to change in the blade frequencles.

To establish the effects of alternate fre quency mistuning on flutter, the frequencies of the even blades were increased by 10 percent and those of the odd blades were decreased by the same per cent (Case 6). Alternate blade frequency mistuning is considered because the beneficial effects on flutter are "robust" for this kind of mistuning in turbofan rotors, see Refs. 10, 12, and 18. From this established relationship between the adverse cascade effects and beneficial alternate frequency mistuning effects (Ref. 10), the expected range of the flutter Mach number for the Case 6 is between 0.46 (Case 4) and 0.63 (Case 3 ). To be beneficial 
as a passive flutter control, the flutter Mach number for case 6 should be greater than 0.59 (Case 5). But the calculated flutter Mach number for Case 6 is 0.53 . Hence, it is concluded that alternate frequency mistuning does not have enough potential to be used as a passive control to increase flutter speed of this $k$ ind of propfan. However, mistuning should be included in the analysis to assess the effective damping of each interblade phase angle mode because the damping is affected significantly by the presence of mistuning as seen in Fig. 7. The fact that the flutter Mach number for case 6 is lower than expected from turbofan studles may be due to the strong coupling between bending and torsion and blade sweep. Unfortunately, no attempt was made in this paper to isolate the aerodynamic and structural effects of blade sweep even though the analytical model has the provision to account for it. Comparing the effects of blade alternate frequency mistuning on turbofan and propfan flutter, it appears that the beneficlal effects of this kind of mistuning in propfan rotors are nullified by the adverse effects of the lower alternate blade frequencles. An interesting point to be noted from Table III is that the critical interblade phase angle varies with the blade frequencles and number of blades. It also varies with blade pitch angle, as was shown in Ref. 5.

\section{CONCLUSIONS}

An analytical and experimental investigation on the effect of both structural and aerodynamic mistuning on propfan subsontc flutter was conducted. An aeroelastic model for the analysis of propfan flutter with mistuning was developed and was validated for selected cases by comparing the calculated and measured flutter characteristics of a propfan wind tunnel model with composite blades. It was found that the correlation between theoretical and experimental flutter Mach numbers is good. But the calculated frequencies are higher than the measured by approximately about 3 to 6 percent. Both theory and experiment also showed that combined mode shape, frequency and aerodynamic mistuning can have either a beneficial or adverse effect on blade damping depending on the Mach number. Additional parametric resuits showed that alternate blade frequency mistuning does not have enough potential for it to be used as a passive control to alleviate flutter in propfans simflar to the one studied herein. The beneficlal effects of blade alternate frequency mistuning on flutter were nullifled by the adverse effects of blade frequency drop due to alternate frequency mistuning. Finaliy, it is inferred from both theoretical and experimental results that a laminated composite propfan blade can be tallored to optimize its flutter speed by selecting the proper ply angles.

\section{References}

1. Mehmed, O., Kaza, K.R.V., Lubomsk1, J.F. and Klelb, R.E.. "Bending-Torsion flutter of a Highly Swept Advanced Turboprop." NASA TM-82975, 1982.

2. Elchur1, v. and Smith, G.C.C., "Flutter Analysis of Advanced Turbopeliers, "AIAA Paper 83-0846. May 1983.
3. Turnberg, 3.E. "Classical Flutter Stability of Swept Propellers." AIAA Paper 83-0847. May 1983.

4. Mehmed, 0. and Kaza, K.R.V., "Experimental Classical flutter Results of a Composite Advanced Turboprop Mode 1," NASA TM-88792, 1986.

5. Kaza, K.R.V., Mehmed, 0., Narayanan, G.V., and Murthy, O.V., "Flutter Investigation of a Composite Advanced Propfan Model, " AIAA Paper 87-0738, Apr. 1987.

6. Chamis, C.C.. "Integrated Analysis of Engine Structures," NASA TM-82713, 1981.

7. "The NASTRAN Theoretical Manual," NASA SP-221(06), 1981.

8. W1lliams, M.H. and Hwang, C., "Three Dimensional Unsteady Aerodynamics and Aeroelastic Response of Advanced Turboprops," AIAA Paper 86-0846. May 1986.

9. Whitehead, D.S., "Effect of Mistuning on the Vibration of Turbo-machine Blades Induced by wakes," Journal of Mechantcal Engineering Science, Vol. 8, No. 1, Mar. 1966, pp. 15-21.

10. Kaza, K.R.V. and Kielb, R.E., "Flutter and Response of a Mistuned Cascade in Incompressible flow," AIAA Journal, Vol. 20. No. 8, Aug. 1982, pp. $1120-1127$.

11. Srinivasan, A.V., "Influence of Mistuning on Blade Torsional Flutter." United Technologies Research Center, East Hartford, CT, R80-974545-116, Aug. 1980. (NASA CR-165137)

12. Kaza, K.R.V. and Kielb, R.E., "flutter of Turbofan Rotors with Mistuned Blades," AIAA Journal, Vol. 22, No. 11, Nov. 1984, Pp. $1618-1625$.

13. Dugundf1, J. and Bundas, D.J., "Flutter and Forced Response of Mistuned Rotors Using Standing Wave Analysis". AIAA Journal. vol. 22, No. 11, Nov. 1984, pp. 1652-1661.

14. Hoynlak, D. and Fleeter, S., "Forced Response of an Aerodynamically Detuned Supersonic Turbo machine Rotor," vibrations of Blades and Bladed O1sk Assemblies, R.E. Kielb and N.F. Rieger, eds., ASME, New York, 1985, pp. 1-3.

15. Willtams, M.H., "An Unsteady Lifting Surface Theory for Single Rotation Propellers." Purdue University Report, June 1985.

16. Willtams, M.H., "User's Guide to UPROP3S," Purdue University Report, Jan. 1985.

17. Turnburg, J.E., "Unstalled Flutter Stability Predictions and Comparisons to Test Data for the SK 3C-X2 Model Propfan." NASA CK. 179512 , 1987 .

18. Crawly, E.F. and Hall, K.C.. "Optimization and Mechartisms of Mistuning in Cascades, "Journal of Engineering for Gas Turbines and Power, Vo1. 107, No. 2, Apr. 1985, pp. 418.426 
TABLE I. - NONROTATING BLADE MEASUREO FREQUENCIES

\begin{tabular}{|c|c|c|c|c|c|c|}
\hline \multirow{2}{*}{$\begin{array}{c}\text { Rotor } \\
\text { configuration }\end{array}$} & \multirow{2}{*}{$\begin{array}{l}\text { Blade } \\
\text { type }\end{array}$} & \multirow{2}{*}{$\begin{array}{c}\text { Number of } \\
\text { blades }\end{array}$} & \multicolumn{2}{|c|}{ Mode 1} & \multicolumn{2}{|c|}{ Mode 2} \\
\cline { 3 - 7 } & & & Average & Range & Average & Range \\
\hline SR3C-X2 & $-X 2$ & 8 & 191 & $185-197$ & 371 & $362-383$ \\
SR3C-X2/ & $-X 2$ & 4 & 189 & $185-193$ & 369 & $363-378$ \\
SR3C-3 & -3 & 4 & 188 & $185-190$ & 415 & $415-416$ \\
\hline
\end{tabular}

table il. - measured and calculated phase angles for the SR3C-X2/SR3C- 3 ROTOR AT A BLADE ANGLE OF $61.2^{\circ}$

\begin{tabular}{|c|c|c|c|c|c|c|c|c|c|c|}
\hline \multirow[b]{3}{*}{ Blades $\rightarrow$} & \multicolumn{8}{|c|}{ Measured } & \multicolumn{2}{|c|}{ Calculated } \\
\hline & \multicolumn{4}{|c|}{$\sigma_{r}$, deg } & \multicolumn{4}{|c|}{$\sigma_{G}$, deg } & \multirow{2}{*}{$\begin{array}{l}\sigma_{r}, \\
\text { deg }\end{array}$} & \multirow{2}{*}{$\begin{array}{l}\sigma_{G}, \\
\text { deg }\end{array}$} \\
\hline & $1-2$ & $3-4$ & $5-6$ & $7-8$ & $1-3$ & $3-5$ & $5-7$ & $7-1$ & & \\
\hline RPM & & & & & & & & & & \\
\hline $\begin{array}{l}5230 \\
6750 \\
7450\end{array}$ & $\begin{array}{l}154 \\
138 \\
139\end{array}$ & $\begin{array}{l}326 \\
175 \\
188\end{array}$ & $\mid \begin{array}{l}121 \\
-- \\
--\end{array}$ & $\begin{array}{l}192 \\
236 \\
229\end{array}$ & $\begin{array}{l}324 \\
211 \\
205\end{array}$ & $\begin{array}{l}250 \\
148 \\
134\end{array}$ & $\begin{array}{l}-- \\
\cdots \\
-\end{array}$ & $\begin{array}{l}224 \\
202\end{array}$ & $\begin{array}{l}155 \\
155 \\
146\end{array}$ & $\begin{array}{r}180 \\
90 \\
90\end{array}$ \\
\hline
\end{tabular}

aThe phase angle of blades A-B is that of $B$ with respect to $A$.

TABLE III. - FREQUENCY MISTUNING STUDY OF THE SR3C-X2 PROPFAN; BLADE ANGLE, $61.2^{\circ}$, ROTATIONAL SPEED, $6320 \mathrm{RPM}$

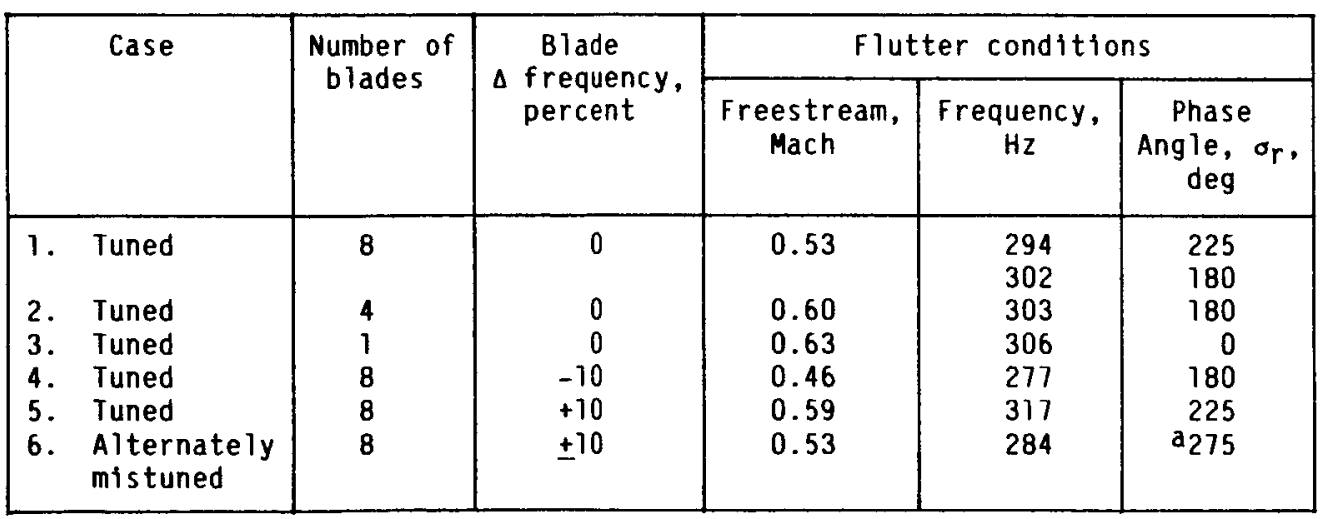

aThe corresponding group phase angle is $90^{\circ}$. 


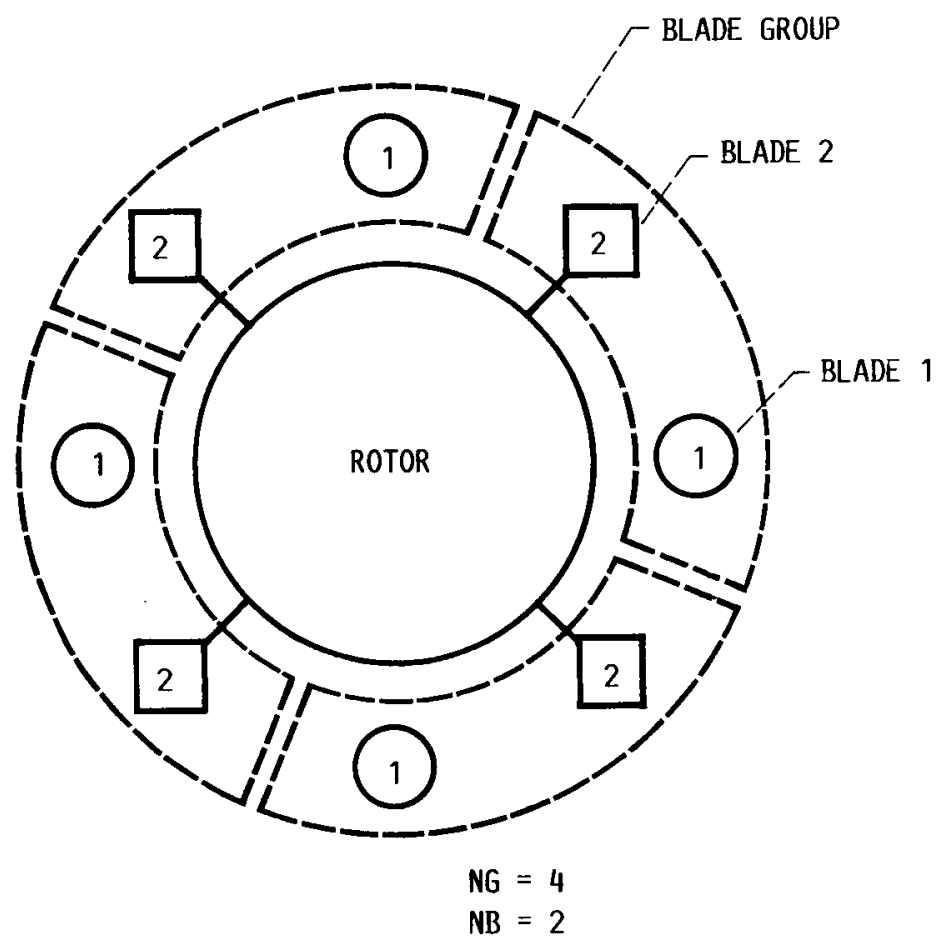

FIGURE 1.- BLADE GROUP SCHEMATIC FOR AN EIGHT-BLADED ROTOR. 


\section{ORGMA}

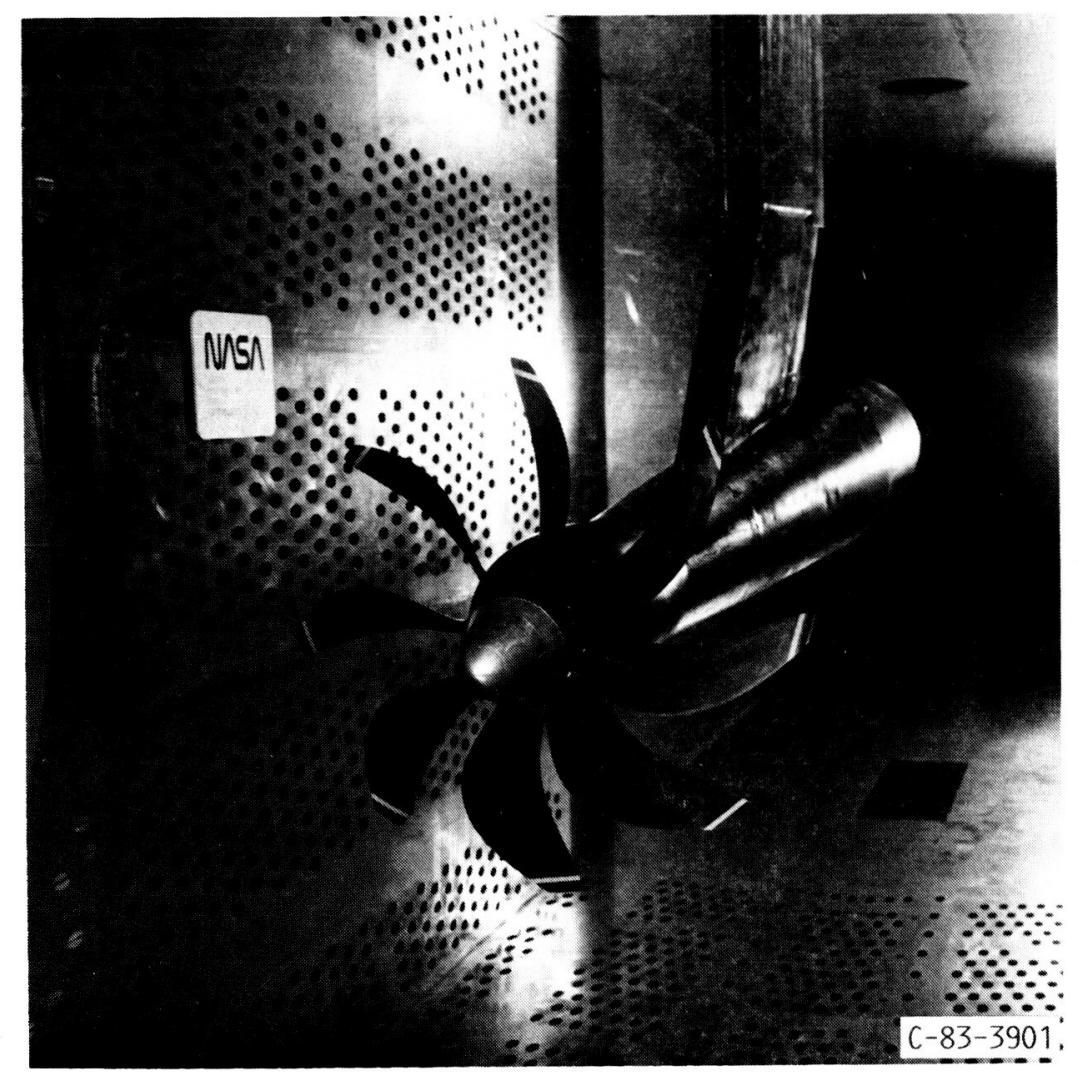

FIGURE 2.- SR3C-X2 PROPFAN MODEL WIND TUNNEL INSTALLATION. 


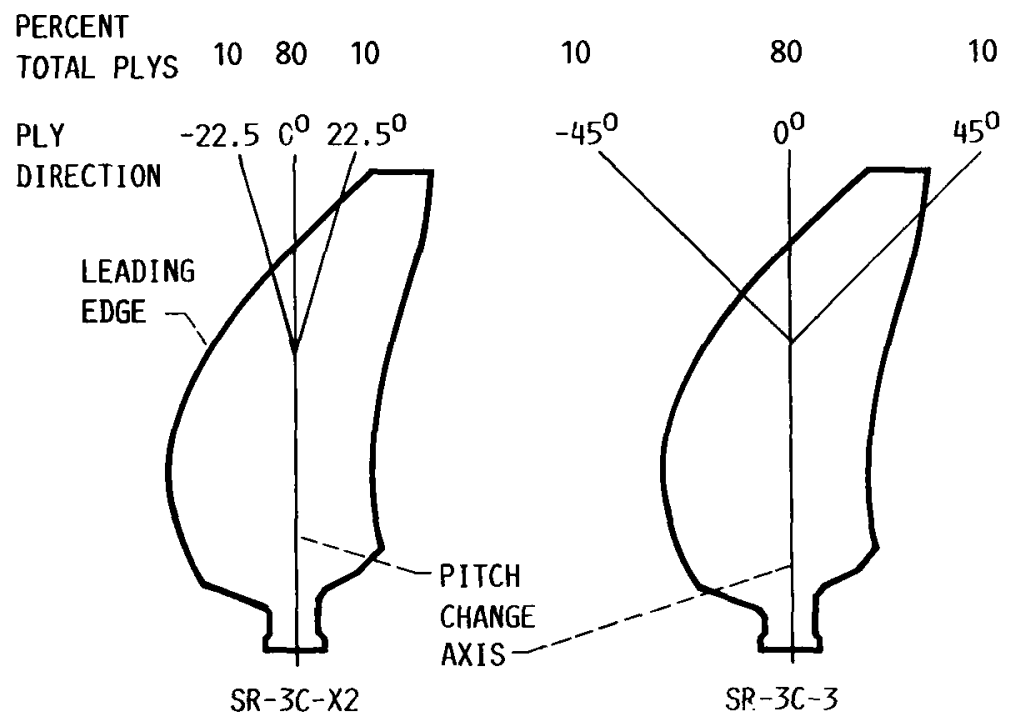

FIGURE 3.- BLADE PLY DIRECTIONS. 


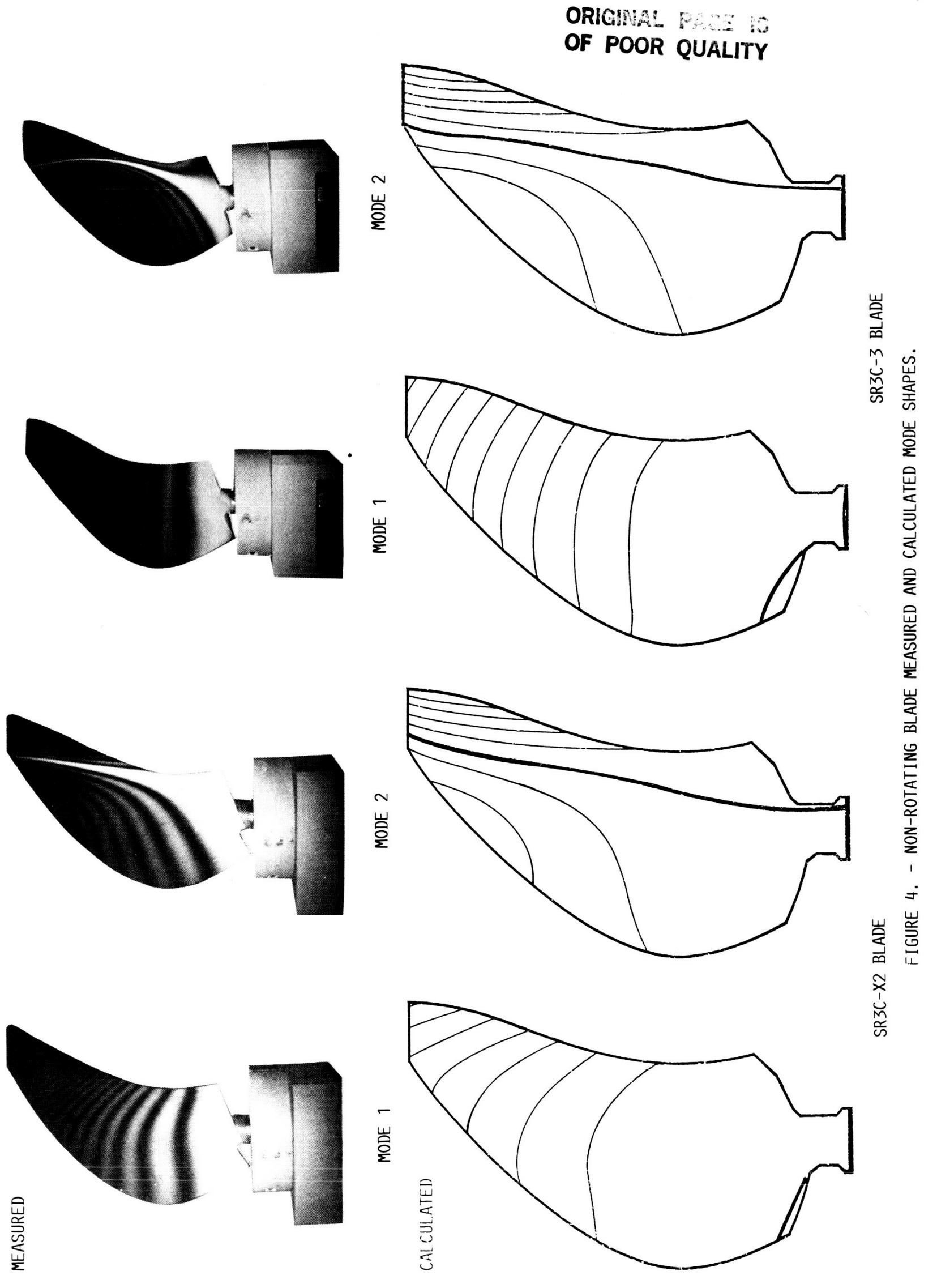




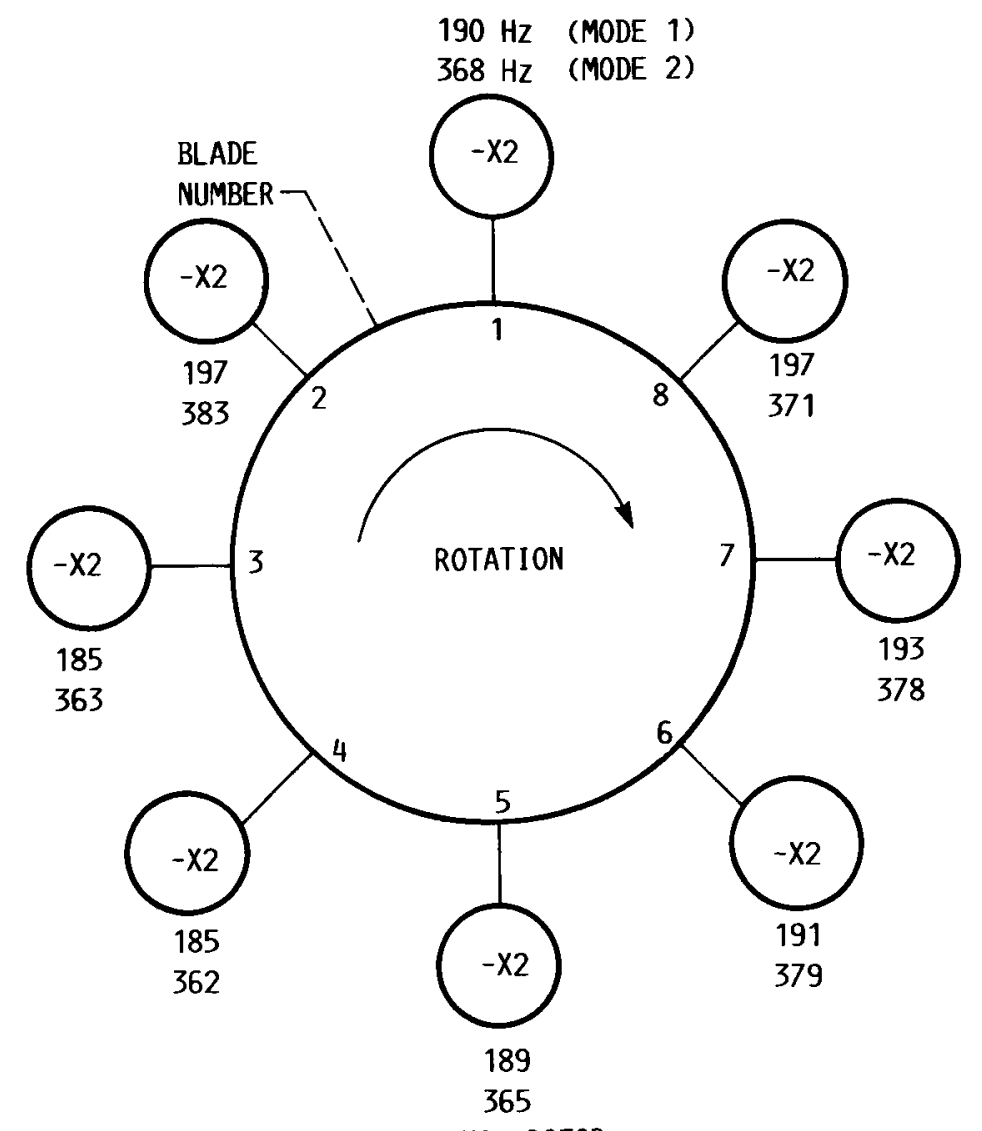

(A) $S R 3 C-X 2$ ROTOR

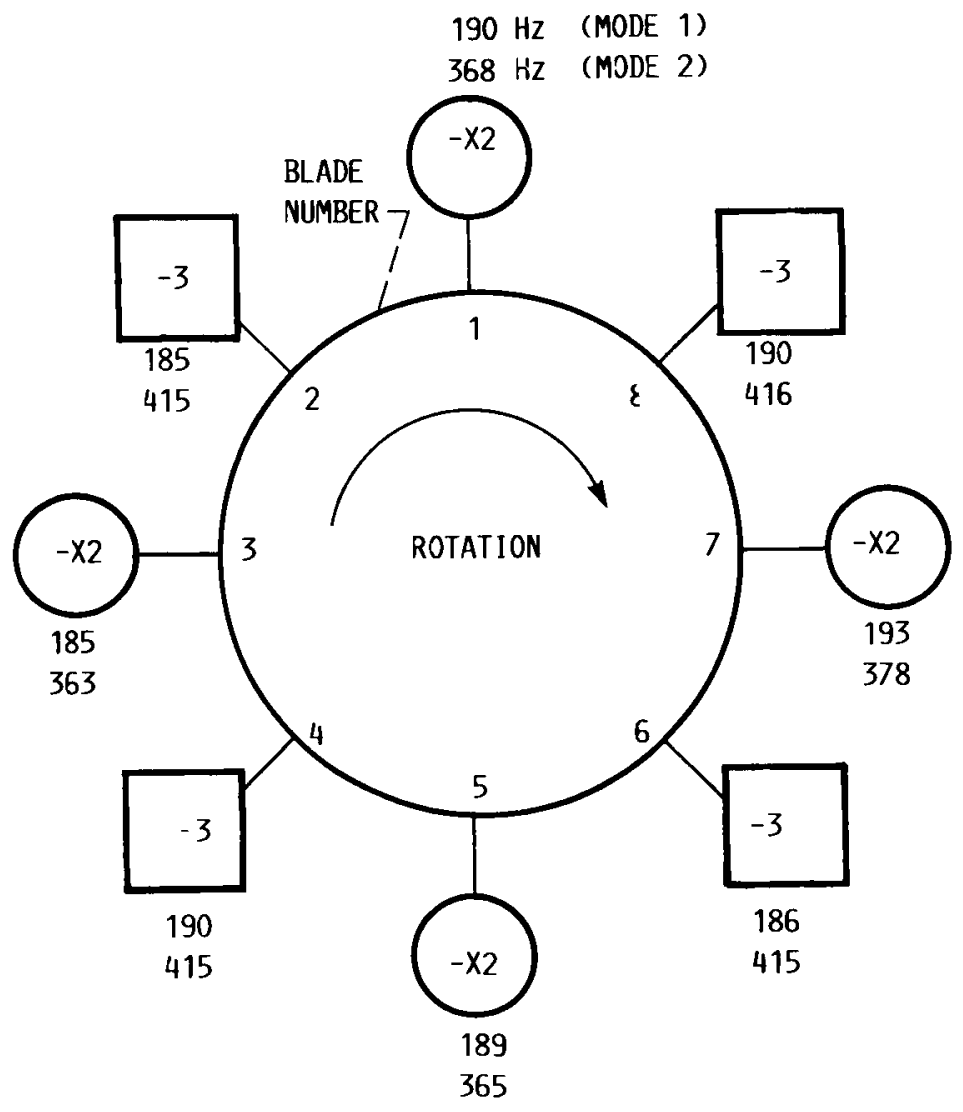

(B) $S R 3 C-X 2 / S R 3 C-3$

ROTOR

FIGURE 5.- NON-ROTATING BLADE FREQUENCY DISTRIBUTION AROUND THE ROTORS. 


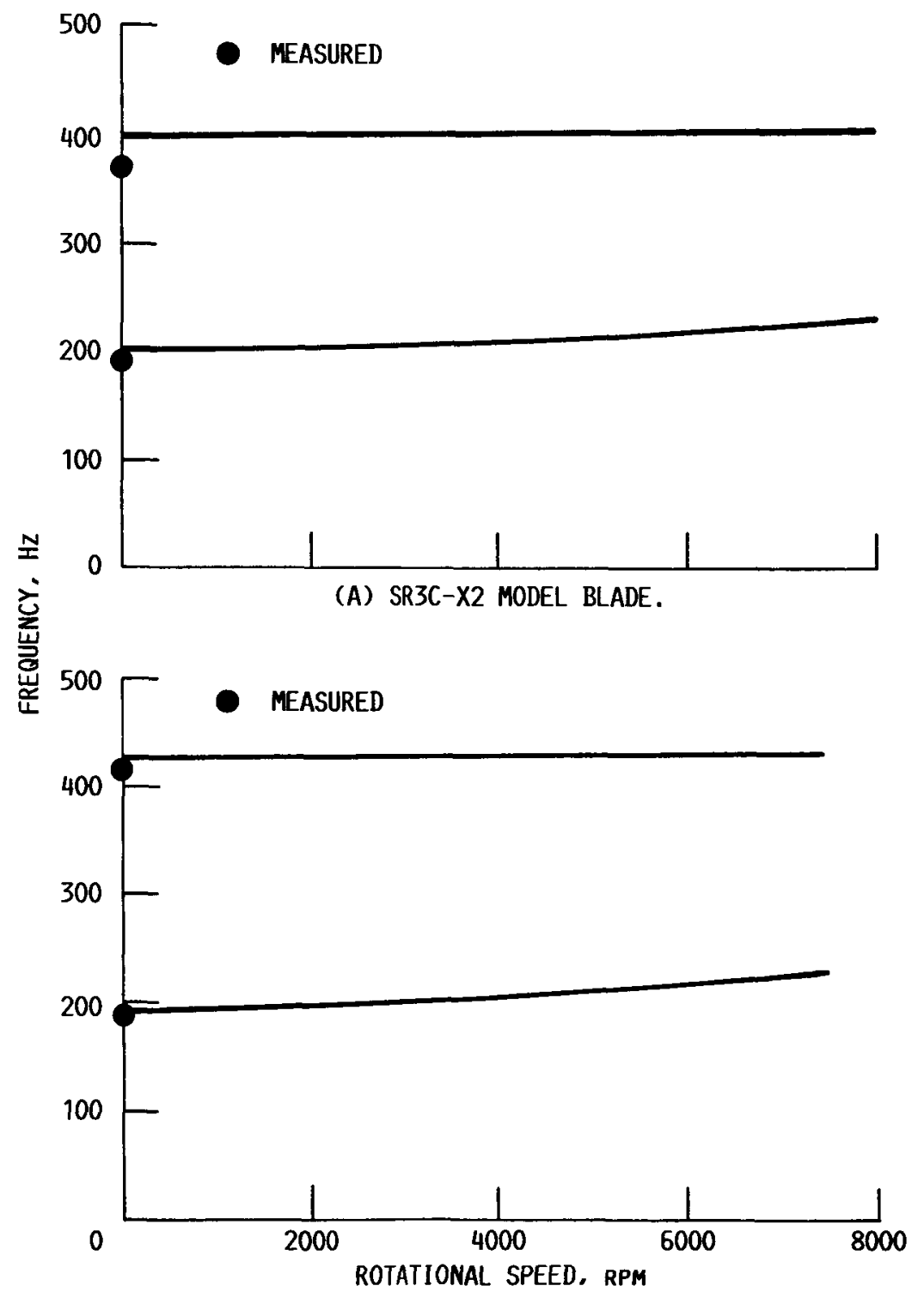

(B) SR3C-3 MODEL BLADE.

FIGURE 6. - CALCULATED VARIATION OF BLADE NATURAL FREQUENCIES WITH ROTATION AT $61.2^{\circ}$ BLADE ANGLE. 


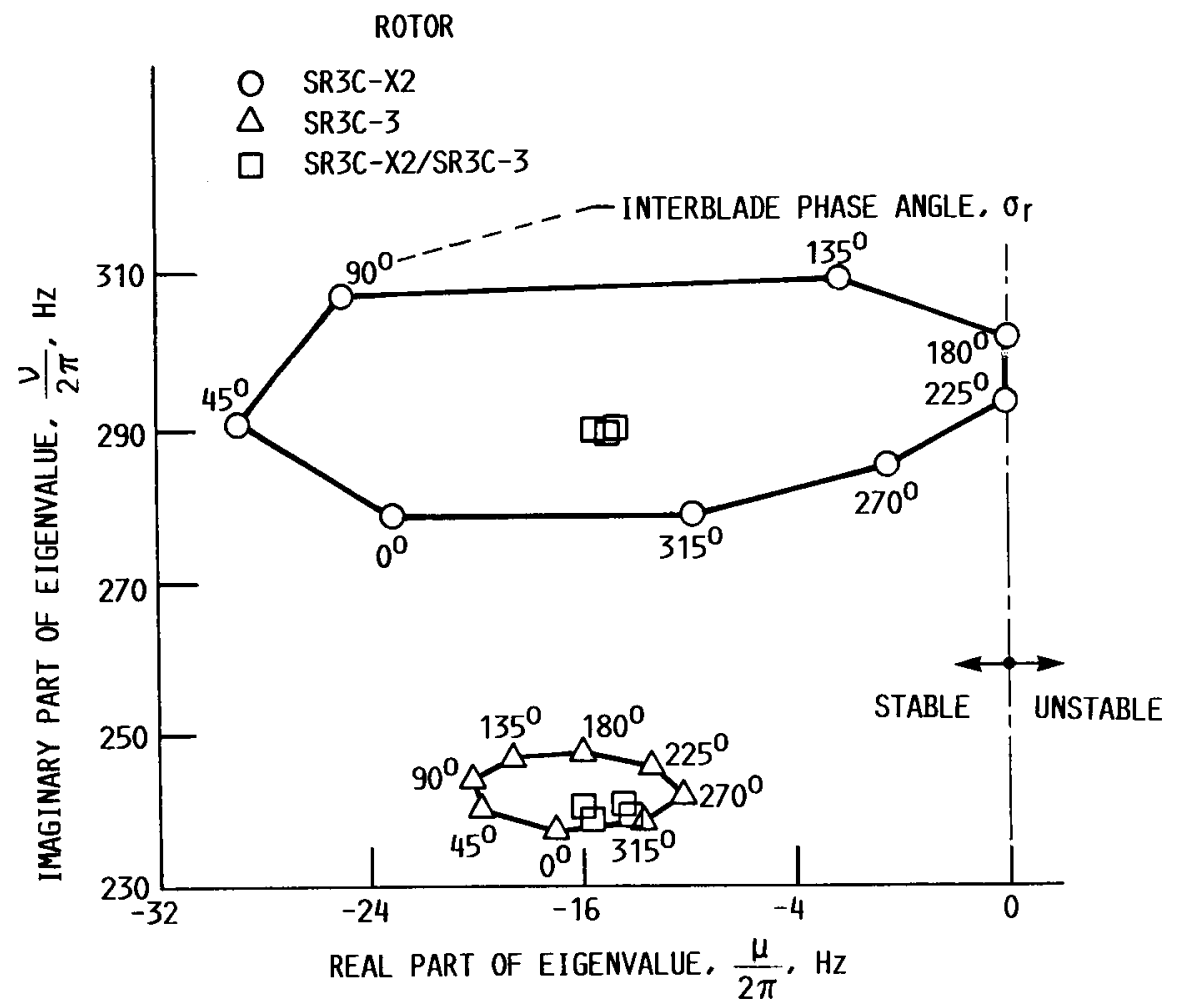

FIGURE 7. - CALCULATED ROOT LOCUS PLOT OF THE LOWEST DAMPED MODE FOR THE SR3C-X2, SR3C-3, AND SR3C-X2/ SR3C-3 ROTORS AT $61.2^{\circ}$ BLADE ANGLE, 6320 RPM AND 0.528 FREESTREAM MACH NUMBER. 


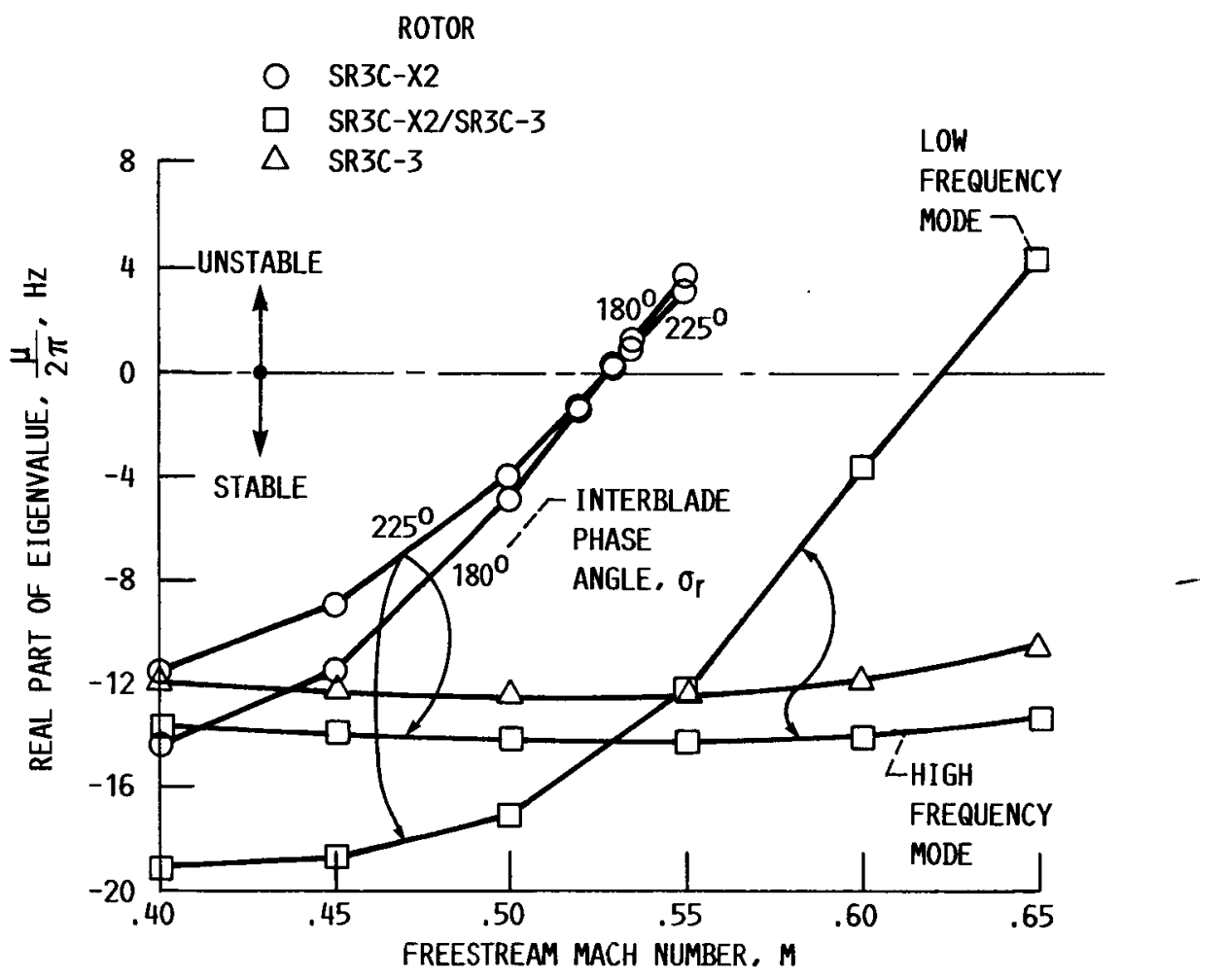

FIGURE 8. - VARIATION OF CALCULATED DAMPING WITH MACH NUMBER FOR THE SR3C-X2 AND SR3C-X2/SR3C-3 ROTORS AT $61.2^{\circ}$ BLADE ANGLE AND 6320 RPM. 


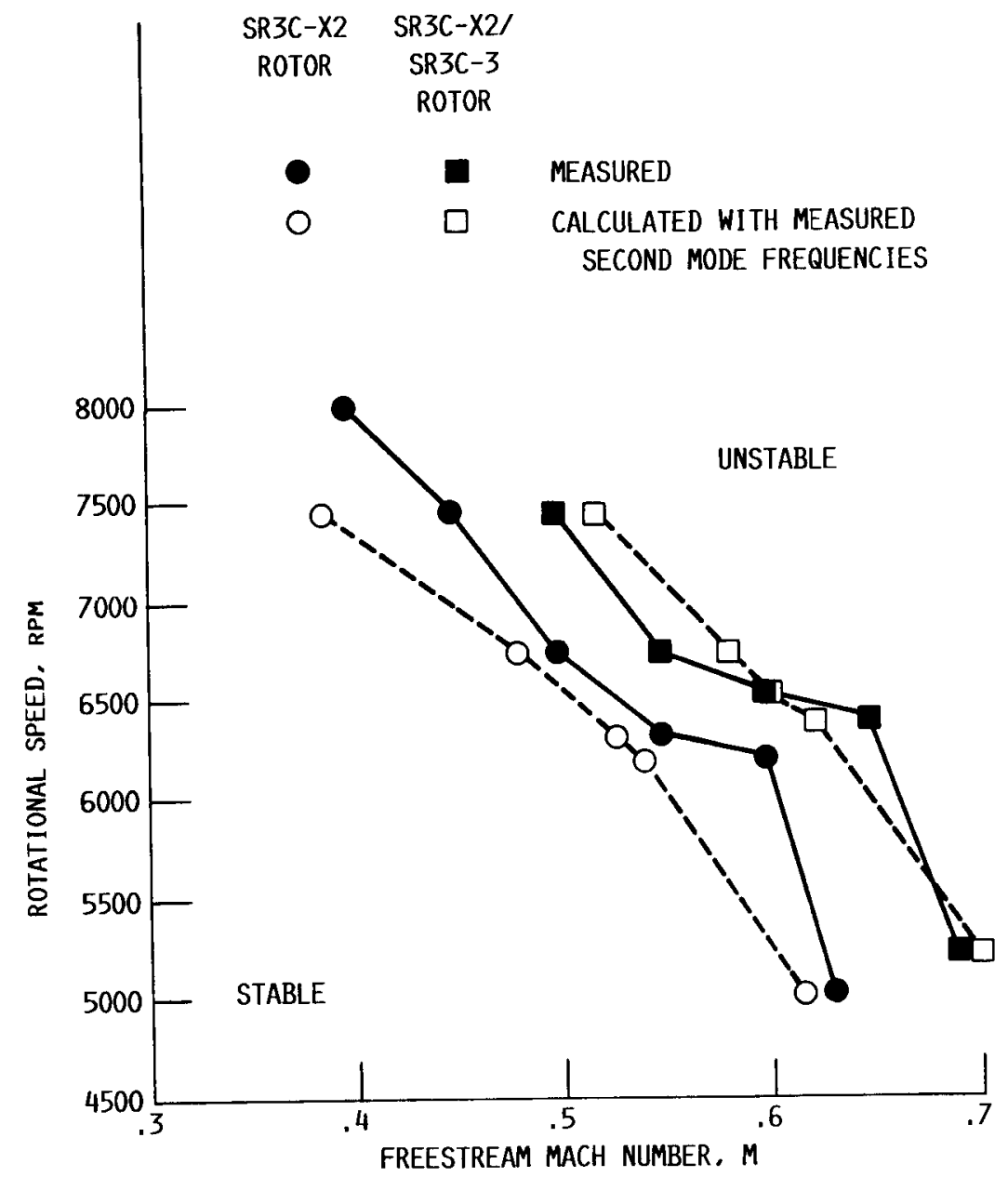

FIGURE 9. - MEASURED AND CALCULATED FLUTTER BOUNDARIES AT $61.2^{\circ}$ BLADE ANGLE. 


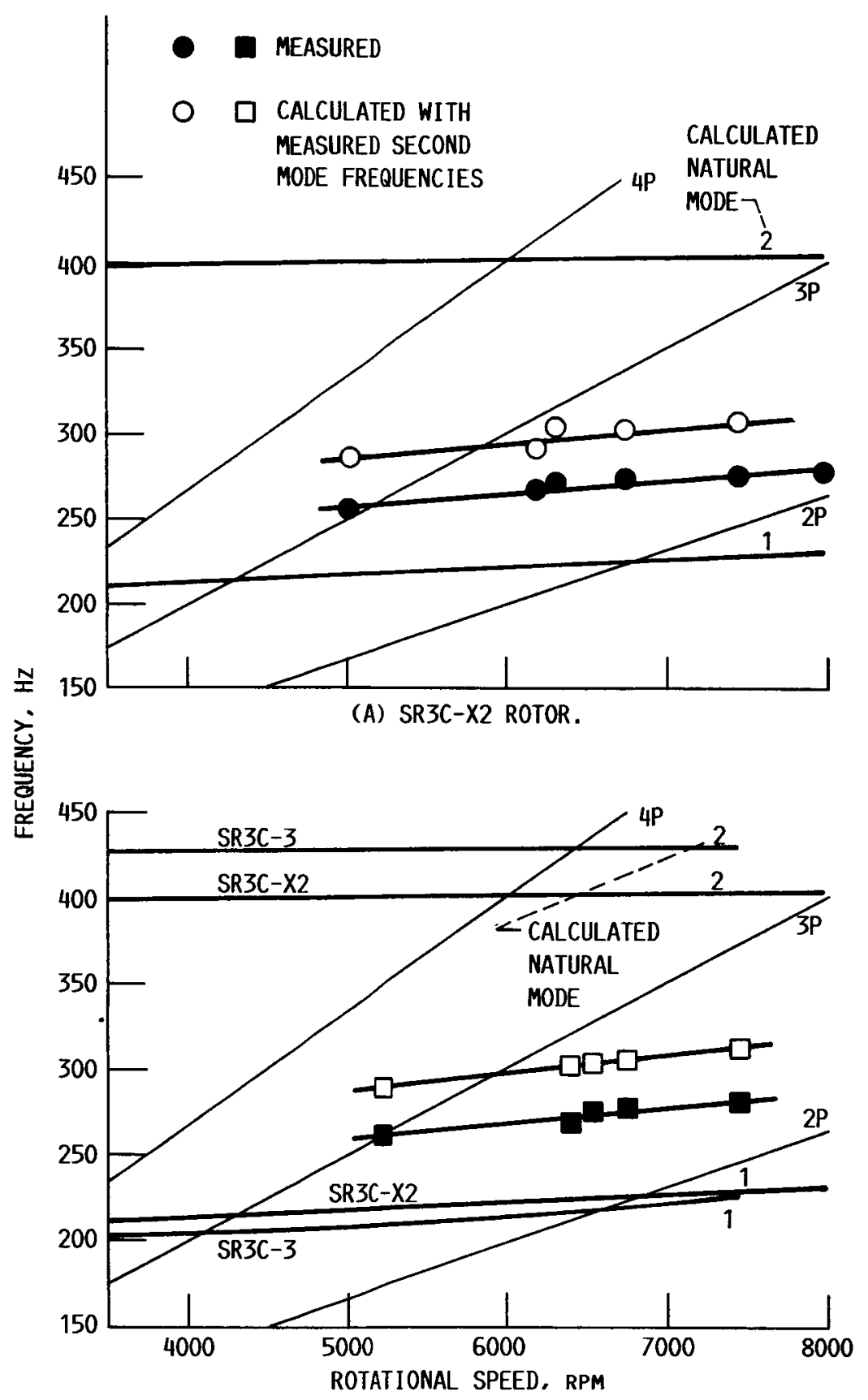

(B) $S R 3 C-X 2 / S R 3 C-3$ ROTOR.

FIGURE 10. - MEASURED AND CALCULATED FLUTTER FREQUENCIES AT 61.2 DEG BLADE ANGLE. 


\begin{tabular}{|c|c|c|c|}
\hline $\begin{aligned} & \text { 1. Report No. } \text { NASA TM-88959 } \\
& \text { AIAA } 87-0739\end{aligned}$ & 2. Government Accession No. & \multicolumn{2}{|l|}{ 3. Recipient's Catalog No. } \\
\hline \multirow{3}{*}{\multicolumn{2}{|c|}{$\begin{array}{l}\text { 4. Title and Subtitle } \\
\text { Analytical and Experimental Investigation of } \\
\text { Mistuning in Propfan Flutter }\end{array}$}} & \multirow{2}{*}{\multicolumn{2}{|c|}{ 5. Report Date }} \\
\hline & & & \\
\hline & & \multicolumn{2}{|c|}{$\begin{array}{l}\text { 6. Performing Organization Code } \\
505-63-11\end{array}$} \\
\hline \multirow{2}{*}{\multicolumn{2}{|c|}{$\begin{array}{l}\text { 7. Author(s) } \\
\text { Krishna Rao V. Kaza, Oral Mehmed, Marc Williams, } \\
\text { and Larry A. Moss }\end{array}$}} & \multicolumn{2}{|c|}{$\begin{array}{l}\text { 8. Performing Organization Report No. } \\
\text { E-3412 }\end{array}$} \\
\hline & & \multicolumn{2}{|l|}{ 10. Work Unit No. } \\
\hline \multirow{3}{*}{\multicolumn{2}{|c|}{$\begin{array}{l}\text { 9. Performing Organization Name and Address } \\
\text { National Aeronautics and Space Administration } \\
\text { Lewis Research Center } \\
\text { Cleveland, Ohio } 44135\end{array}$}} & & \\
\hline & & \multicolumn{2}{|l|}{ 11. Contract or Grant No. } \\
\hline & & \multirow{2}{*}{\multicolumn{2}{|c|}{$\begin{array}{l}\text { 13. Type of Report and Period Covered } \\
\text { Technical Memorandum }\end{array}$}} \\
\hline \multirow{2}{*}{\multicolumn{2}{|c|}{$\begin{array}{l}\text { 12. Sponsoring Agency Name and Address } \\
\text { National Aeronautics and Space Administration } \\
\text { Washington, D.C. } 20546\end{array}$}} & & \\
\hline & & \multicolumn{2}{|l|}{ 14. Sponsoring Agency Code } \\
\hline \multicolumn{4}{|c|}{$\begin{array}{l}\text { 15. Supplementary Notes } \\
\text { Prepared for the } 28 \text { th Structures, Structural Dynamics, and Materials Conference, cosponsored by the } \\
\text { AIAA, ASME, AHS, and ASFE, Monterey, California, April 6-8, 1987, Krishna Rao V. Kaza and Oral Metmed, } \\
\text { NASA Lewis Research Center; Marc Williams, School of Aeronautics and Astronautics, Purdue University, } \\
\text { West Lafayette, Indiana } 47907 \text {; Larry A. Moss, Sverdrup Technology, Inc., Lewis Research Center, } \\
\text { Cleveland, Ohio } 44135 \text {. }\end{array}$} \\
\hline \multicolumn{4}{|c|}{$\begin{array}{l}\text { An abstract } \\
\text { subsonic flutter has been performed. The analytical model is based on the normal } \\
\text { modes of a rotating composite blade and a three-dimensional subsonic unsteady lift- } \\
\text { ing surface aerodynamic theory. Theoretical and experimental results are compared } \\
\text { for selected cases at different blade pitch angles, rotational speeds and free- } \\
\text { stream Mach numbers. The comparison shows a reasonably good agreement between } \\
\text { theory and experiment. Both theory and experiment showed that combined mode shape, } \\
\text { frequency, and aerodynamic mistuning can have a beneficial or adverse effect on } \\
\text { blade damping depending on Mach number. Additional parametrie results showed that } \\
\text { alternate blade frequency mistuning does not have enough potential for it to be } \\
\text { used as a passive flutter control in propfans similar to the one studied herein. } \\
\text { It can be inferred from the results that a laminated composite propfan blade can be } \\
\text { tailored to optimize its flutter speed by selecting the proper ply angles. }\end{array}$} \\
\hline \multicolumn{4}{|c|}{\begin{tabular}{l|l} 
17. Key Words (Suggested by Author(s)) & 18. Distribution Statement \\
Flutter; Mistuning; Propfan; & Unclassified - unilimited \\
Vibration & SIAR Category 39
\end{tabular}} \\
\hline $\begin{array}{l}\text { 19. Security Classif. (of this report) } \\
\text { Unc las s if I Ied }\end{array}$ & $\begin{array}{l}\text { Security Classif. (of this page) } \\
\text { Unc las } 5 \text { if ied }\end{array}$ & 21. No. of pages 19 & 22. Price" $\mathrm{AO2}$ \\
\hline
\end{tabular}

"For sale by the National Technical Information Service, Springfield, Virginia 22161 